\title{
Neonatal Constipation, AE
}

National Cancer Institute

\section{Source}

National Cancer Institute. Neonatal Constipation, AE. NCI Thesaurus. Code C154946.

An adverse event in a newborn characterized by irregular and infrequent or difficult evacuation of the bowels. 